\title{
Engineering a feedback inhibition-insensitive plant dihydrodipicolinate synthase to increase lysine content in Camelina sativa seeds
}

\author{
Alex Huang • Cathy Coutu • Myrtle Harrington • Kevin Rozwadowski • \\ Dwayne D. Hegedus 1
}

Received: 26 May 2021 / Accepted: 11 November 2021 / Published online: 20 November 2021

(C) Crown 2021

\begin{abstract}
Camelina sativa (camelina) is emerging as an alternative oilseed crop due to its short growing cycle, low input requirements, adaptability to less favorable growing environments and a seed oil profile suitable for biofuel and industrial applications. Camelina meal and oil are also registered for use in animal and fish feeds; however, like meals derived from most cereals and oilseeds, it is deficient in certain essential amino acids, such as lysine. In higher plants, the reaction catalyzed by dihydrodipicolinate synthase (DHDPS) is the first committed step in the biosynthesis of lysine and is subject to regulation by lysine through feedback inhibition. Here, we report enhancement of lysine content in $C$. sativa seed via expression of a feedback inhibition-insensitive form of DHDPS from Corynebacterium glutamicums (CgDHDPS). Two genes encoding $C$. sativa DHDPS were identified and the endogenous enzyme is partially insensitive to lysine inhibition. Site-directed mutagenesis was used
\end{abstract}

Supplementary Information The online version contains supplementary material available at https://doi.org/10.1007/ s11248-021-00291-6.

A. Huang $\cdot$ C. Coutu $\cdot$ M. Harrington .

K. Rozwadowski · D. D. Hegedus ( $\square)$

Agriculture and Agri-Food Canada, 107 Science Place,

Saskatoon, SK S7N 0X2, Canada

e-mail: Dwayne.Hegedus@canada.ca

D. D. Hegedus

Department of Food and Bioproduct Sciences, University

of Saskatchewan, Saskatoon, SK, Canada to examine the impact of alterations, alone and in combination, present in lysine-desensitized DHDPS isoforms from Arabidopsis thaliana DHDPS (W53R), Nicotiana tabacum (N80I) and Zea mays (E84K) on C. sativa DHDPS lysine sensitivity. When introduced alone, each of the alterations decreased sensitivity to lysine; however, enzyme specific activity was also affected. There was evidence of molecular or structural interplay between residues within the $C$. sativa DHDPS allosteric site as coupling of the W53R mutation with the N80V mutation decreased lysine sensitivity of the latter, but not to the level with the W53R mutation alone. Furthermore, the activity and lysine sensitivity of the triple mutant (W53R/N80V/ E84T) was similar to the W53R mutation alone or the C. glutamicum DHDPS. The most active and most lysine-insensitive $C$. sativa DHDPS variant (W53R) was not inhibited by free lysine up to $1 \mathrm{mM}$, comparable to the $C$. glutamicums enzyme. Seed lysine content increased $13.6-22.6 \%$ in CgDHDPS transgenic lines and 7.6-13.2\% in the mCsDHDPS lines. The high lysine-accumulating lines from this work may be used to produce superior quality animal feed with improved essential amino acid profile.

Keywords Camelina sativa $\cdot$ Lysine .

Dihydrodipicolinate synthase $\cdot$ Corynebacterium glutamicum $\cdot$ Feedback inhibition 


\section{Introduction}

Camelina sativa (camelina), an oilseed crop belonging to the Brassicaceae family, has emerged as a platform for aviation biofuel and various other industrial applications (Bansal and Durrett 2016). It is being developed as a sustainable rotation crop due to its short lifecycle (100-120 days) and reasonable productivity on marginal lands with low inputs (Vollmann and Eynck 2015). The seed oil contains $50-60 \%$ polyunsaturated fatty acids, of which $20-25 \%$ is omega 6 (linoleic acid, 18:2n-6) and 35-40\% is omega 3 (linolenic acid, 18:3n-3) (Lu and Kang 2008). $\alpha$ linolenic acid is the precursor for the essential long chain polyunsaturated fatty acids eicosapentanoic acid

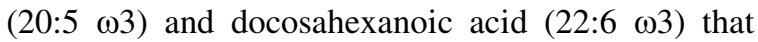
have human health benefits. Camelina seed meal generated by cold-pressing is rich in protein $(450 \mathrm{~g}$ $\left.\mathrm{Kg}^{-1}\right)$ and residual oil $\left(100 \mathrm{~g} \mathrm{Kg}^{-1}\right)$ and can be used as a source of protein in farmed fish (Hixson and Parish 2014; Hixson et al. 2014; 2016a,b), poultry (Kakani et al. 2012), and livestock (Cappellozza et al. 2012; Colombini et al. 2014; Kahindi et al. 2014). Atlantic cod (Gadus morhua) tolerated up to $24 \%$ inclusion of camelina meal in place of fish meal in their diets without affecting weight gain (Hixson et al. 2016a); however, the levels of several essential amino acids are limiting as in most plant-based diets (Zubr 2003; Galili et al. 2016). Lysine and methionine, in particular, are often added as supplements to fish (Wilson and Halver 1986), poultry (Kidd et al. 1998) and swine feed (Brinegar et al. 1950) diets.

Improvement in the essential amino acid profile would increase camelina meal inclusion rates in feed. High-lysine corn varieties have been obtained through traditional breeding, as exemplified by the opaque 2 mutation (Mertz et al. 1964); however, this is linked to inferior agronomic traits. Improved Quality Protein Maize was successfully developed for commercial applications (Gibbon and Larkins 2005), but progress has been slow for other crops. Lysine content has been increased in cereal grains through transgenic expression of high lysine proteins, such as endogenous histones (Wong et al. 2015), BiP chaperone (Kawakatsu et al. 2010) or lysine-enriched fusion proteins (Yu et al. 2005; Chang et al. 2015; Liu et al. 2016; Jiang et al. 2016). Similar approaches have been taken with dicotyledonous species, including Nicotiana tabacum (Keeler et al. 1997), Glycine max (Zhang et al. 2014) and Brassica napus (Wang et al. 2011). Increased lysine content has also been achieved by suppressing the accumulation of low lysine seed storage proteins in B. napus (Kohno-Murase et al. 1995) and cereals (Kim et al. 2013; Schmidt et al. 2016).

Lysine and three other essential amino acids (methionine, isoleucine, and threonine) are derived from the aspartic acid pathway (Jander and Joshi 2010; Atkinson et al. 2012a; Galili et al. 2016; Wang et al. 2018). A crucial rate-limiting steps in lysine biosynthesis is catalyzed by the enzyme dihydrodipicolinate synthase (DHDPS; EC 4.2.2.52) (Galili 2002; Zhu and Galili 2003; Silk and Matthews 1997; Wang et al. 2018), which catalyses the condensation of pyruvate and $(S)$-aspartate semialdehyde (ASA) to form (4S)-4hydroxy-2,3,4,5-tetrahydro-(2S)-dipicolinic acid (HTPA) (Blickling et al. 1997a). HTPA is further converted into lysine following reduction, amination, epimerization and decarboxylation reactions (Atkinson et al. 2013; Skovpen and Palmer 2013). Plant DHDPS enzymes are encoded by the dapA gene and localized to plastids (Ghislain et al. 1990) where their activity is regulated through feedback inhibition by free lysine (Jander and Joshi 2010) (Dereppe et al. 1992; Frisch et al. 1991; Ghislain et al. 1990; Kumpaisal et al. 1987; Negrutiu et al. 1984). Expression of lysine-insensitive DHDPS variants can increase accumulation of free lysine in plants (Frankard et al. 1992). Increased lysine levels in tobacco leaves (Ghislain et al. 1995) and the ability of a maize DHDPS to complement an Escherichia coli dapA mutation in the presence of an inhibitory lysine analouge (Shaver et al. 1996) were attributed to a lysine-insensitive DHDPS variants with single amino acid changes in their allosteric sites. The E. coli DHDPS is partially-insensitive to lysine and lysine content increased in tobacco seeds when it was coexpressed with a feedback-insensitive aspartate kinase (AK, lysC) (Karchi et al. 1994). The Corynebacterium glutamicum DHDPS (CgDHDPS, CordapA) is insensitive to feedback inhibition and total lysine content increased twofold in B. napus seeds when expressed alone and up to five-fold in soybean seeds when expressed in combination with AK (Falco et al. 1995). In rice, free lysine levels increased up to 12 -fold in leaves and 60-fold in seeds in transgenic lines coproducing the E. coli AK and DHDPS in the chloroplast in combination with RNA interference to reduce 
levels of the catabolic enzyme lysine ketoglutaric acid reductase/saccharopine dehydrogenase (LKR/SDH) (Long et al. 2013). How this affected total lysine content was not determined. Similarly, production of a chloroplast-localized CgDHDPS and suppression of $L K R / S D H$ expression increased free lysine by 40 -fold in transgenic corn seed (Frizzi et al. 2008). In Arabidopsis thaliana, production of a bacterial lysine-insensitive DHDPS in a T-DNA insertion mutant of $L K R / S D H$ synergistically increased free lysine levels 80-fold in the seed (Zhu and Galili 2003, 2004). Expression of CgDHDPS in a maize opaque mutant with reduced levels of the zein storage protein enhanced total lysine accumulation 1.3-fold in the grain (Huang et al. 2005). These data provide unambiguous evidence that manipulation of critical regulatory steps in the lysine biosynthetic pathway (AK, DHDPS and LKR/SDH) can lead to enhanced lysine accumulation in cereal grains and oilseeds. Here we examine the application of CgDHDPS and several engineered lysine-insensitive isoforms of an endogenous $C$. sativa DHDPS for increasing lysine levels in camelina meal.

\section{Materials and methods}

Plant materials and growth conditions

Camelina sativa (L.) Crantz line DH55, the source of the Genbank reference genome (Kagale et al. 2014; 2016), was used in this study. Plants used for phenotyping were grown in RediEarth (W.R. Grace \& Co., Ajax, ON, Canada) in pots in a growth cabinet with the following settings: $16 \mathrm{~h}$ light $/ 8 \mathrm{~h}$ dark and $20^{\circ} \mathrm{C}$ day $/ 18{ }^{\circ} \mathrm{C}$ night temperature cycle.

Seed germination and seedling growth assay

Seeds were surface-sterilized with $70 \%$ ethanol for $5 \mathrm{~min}$ and then with a $2.5 \%$ sodium hypochlorite solution (50\% household bleach) for $7 \mathrm{~min}$. After five washes in distilled water, seeds were placed on $0.5 \mathrm{X}$ MS (Murashige and Skoog 1962; pH 6.0), $1 \%$ sucrose, $0.8 \%$ agar plates. Germination was recorded as the emergence of the radical. Seedling growth was monitored on the same media with or without $1.5 \mathrm{mM}$ S-(2-aminoethyl)-L-cysteine (AEC; Sigma), a non-metabolizable analogue of lysine.
Cloning and analysis the DHDPS gene from $C$. glutamicum and $C$. sativa

The $C$. glutamicum DapA (CgDHDPS) open reading frame (ORF) was amplified by polymerase chain reaction (PCR) from the genomic DNA of strain ATCC 130,302 (American Type Culture Collection) using KAPA HotStart DNA polymerase (VWR, Mississauga, ON, Canada) and two gene-specific primers: CgDHDPS-F (EcoRI) and CgDHDPS-R (BamHI) (Supplemental Table S1). The resultant DNA was digested with EcoRI and BamHI and ligated into pUC18 digested with the same restriction enzymes and then transformed into E. coli DH10B. Camelina sativa DH55 DHDPS cDNA was amplified from 100 ng leaf total RNA using the One-Step RTPCR kit (Life Technologies) and two gene-specific primers: CsDHDPS F3 and CsDHDPS R3 (Supplemental Table S1). The resultant cDNA was purified and ligated into pGEM-T Easy (Promega) and transformed into E. coli DH10B. Several independent clones were sequenced to identify isoforms encoded by homoeologous genes. Of the three homoeologues in the camelina genome (Kagale et al. 2014; 2016), two were identified and used for further studies; these were denoted B4 (Csa16g004020) and B6 (Csa05g092770). Chloroplast targeting peptides were detected using the ChloroP 1.1 Server (http://www. cbs.dtu.dk/services/ChloroP-1.1/pages/output-expl. php).

Site-directed mutagenesis of CsDHDPS cDNA

Mutations resulting in single amino acid changes were introduced into regions of CsDHDPS B6 within or adjacent to the allosteric site both independently and in combination. These were designated as CsDHDPS mA (W53R), CsDHDPS mB (N80V) and CsDHDPS $\mathrm{mC}(\mathrm{E} 84 \mathrm{~T})$ according to the numbering of residues in the E. coli DHDPS. CsDHDPS B6 cDNA was cloned into pGEM-T Easy and site-directed mutagenesis (SDM) conducted using the Quick Change SDM kit (Life Technologies). Oligonucleotides used for cloning and mutagenesis are provided in Supplemental Table S1. Plasmid DNA was isolated from E. coli using the Qiaprep Spin Miniprep kit (Qiagen). Primers spanning the SDM site and $P f u$ Turbo high fidelity DNA polymerase (Agilent Technologies) were used to amplify the entire plasmid. DpnI is a restriction 
enzyme specific for methylated DNA and was used to remove the template plasmid leaving only the unmethylated plasmid DNA derived from the PCR. DpnI-digested SDM reaction was used to transform E. coli $\mathrm{DH} 10 \mathrm{~B}$ and plasmids from positive colonies were sequenced to verify the mutations. To combine mutations, N80VB6F and N80VB6R SDM primers were used to integrate the $\mathrm{N} 80 \mathrm{~V}$ mutation $(\mathrm{mB})$ into CsDHDPS B6 W53R (mA) to create the W53R/N80V double mutant (mAB). Similarly, the $\mathrm{mBmC}-\mathrm{F}$ and $\mathrm{mBmC}-\mathrm{R}$ SDM primers were used to integrate the N80V and E84T mutations into CsDHDPS B6 W53R to create the triple mutant (mABC). Complementation of the $\boldsymbol{E}$. coli dapA ${ }^{-}$auxotroph
with $C g D H D P S$ and $C \boldsymbol{S}$ DHDPS

Open reading frames encoding CsDHDPS B4 (364 aa; Csa16g004020) and CsDHDPS B6 (365 aa; Csa05g092770) or mutagenized variants were amplified from the pGEM-T Easy plasmids by PCR using $P f u$ Turbo DNA polymerase (Agilent Technologies) with CsDHDPS-F6 (EcoRI) and CsDHDPS-R6 (KpnI) primers (Supplemental Table S1). The purified fragments were digested and inserted into the EcoRI and $K p n I$ sites of pUC18 in-frame with the LacZ ORF translation start codon. pUC18 plasmids harbouring the CsDHDPS variants or CgDHDPS were introduced into the E. coli dapA $A^{-}$lysine auxotrophic strain AT997 (Genetic Stock Center, Yale University) which contains a defective $d h d p s$ gene and requires supplementation with lysine or diaminopimelic acid (DAP) to maintain normal growth on M9 minimum medium. Transformed colonies were isolated on M9 medium with $100 \mu \mathrm{M}$ DAP and $100 \mu \mathrm{g} / \mathrm{ml}$ ampicillin at $37^{\circ} \mathrm{C}$.

Growth was monitored on M9 medium alone, as well as M9 medium in the presence of $100 \mu \mathrm{M}$ DAP or increasing concentrations of AEC (Sigma). Cells were grown in $10 \mathrm{ml}$ of media in custom-built $50 \mathrm{ml}$ Erlenmeyer flasks fitted with a $10 \mathrm{ml}$ test tube sidearm at $37{ }^{\circ} \mathrm{C}$ with shaking at $225 \mathrm{rpm}$ (Department of Chemistry, University of Saskatchewan). Cell culture was periodically transferred to the sidearm and optical density $\left(\mathrm{A}_{610} \mathrm{~nm}\right)$ recorded with a digital colorimeter (Horizon 5965-50).
DHDPS activity assay

DHDPS-containing cell extract was prepared using a procedure modified from Silk et al. (1994). Briefly, E. coli $\mathrm{DH} 10 \mathrm{~B}$ cells harboring the pUC18 DHDPS plasmids were grown in LB broth supplemented with $100 \mu \mathrm{M}$ DAP, $14.8 \mu \mathrm{M}$ thiamine hydrochloride, $1 \mathrm{mM} \mathrm{MgSO}{ }_{4} \cdot 7 \mathrm{H}_{2} \mathrm{O}, 11 \mathrm{mM}$ D-glucose, $100 \mu \mathrm{g} / \mathrm{ml}$ ampicillin at $37^{\circ} \mathrm{C}$ with shaking $(225 \mathrm{rpm})$. To induce DHDPS expression, $0.5 \mathrm{mM}$ isopropyl $\beta$-D-1-thiogalactopyranoside (IPTG) was added to the cultures when the $\mathrm{OD}_{600}$ reached $0.6-0.8$ and incubated for $6 \mathrm{~h}$. Cells were harvested by centrifugation and pellets washed twice in buffer consisting of $50 \mathrm{mM}$ Tris- $\mathrm{HCl}$ (pH 7.5), $1 \mathrm{mM}$ EDTA, $1 \mathrm{mM}$ 2-mecaptoethanol, $20 \%$ glycerol and $10 \mathrm{mM}$ pyruvate, and re-suspended in $150 \mathrm{ul}$ of fresh buffer. The cells were lysed by sonication for $30 \mathrm{~s}$ and stored at $-20{ }^{\circ} \mathrm{C}$. Total protein concentration was determined using a $\mathrm{Q}$ bit fluorimeter (Life Technologies).

DHDPS activity was measured as previously described (Vauterin et al. 2000) using L-aspartic- $\beta$ semi-aldehyde (L-ASA) as the substrate. Assays were carried out in $1 \mathrm{ml}$ of buffer consisting of $100 \mathrm{mM}$ Tris- $\mathrm{HCl}$ ( $\mathrm{pH} 8), 35 \mathrm{mM}$ pyruvate, $2 \mathrm{mM}$ neutralized L-ASA, $40 \mu \mathrm{l}$ cell extract and $35 \mu \mathrm{l}$ of $o$-aminobenzaldehyde solution $(0.5 \mathrm{mg} o$-ABA/35 $\mu \mathrm{l}$ ethanol). Reactions were incubated at $37^{\circ} \mathrm{C}$ for $30-90 \mathrm{~min}$ depending on the DHDPS activity in the reaction mixtures. The reactions were stopped by addition of $200 \mu 12 \%$ trichloric acid (TCA) and placed in the dark. Under acidic conditions, $o$-ABA and L-2,3dihydrodipicolinate react to form an adduct with a deep purple color (Yugari and Gilvarg 1965; Atkinson et al. 2012b), which develops maximally $2 \mathrm{~h}$ after TCA addition. The adduct is stable for about $6 \mathrm{~h}$ and its' absorption is measured at $520 \mathrm{~nm}$ (Mitsakos et al. 2011; Erzeel et al. 2013; Atkinson et al. 2014). L-ASA was synthesized by Dr. D. Palmer in the Department of Chemistry, University of Saskatchewan, Canada. The effect of free lysine on DHDPS activity was assessed by inclusion of lysine in the reaction mixture at concentrations ranging from $12.5 \mu \mathrm{M}$ to $10 \mathrm{mM}$ depending on the sensitivity of the enzyme. 
Construction of binary vectors and plant transformation

DHDPS is localized to the chloroplasts of higher plants (Wallsgrove and Mazelis 1980), therefore, the amino-terminal chloroplast transit peptide (CTP) from the A. thaliana Rubisco small subunit (At1g67090) was appended to the CgDHDPS. The region encoding the CTP was amplified from A. thaliana genomic DNA using AtCTP-F and AtCTP-R and then reamplified using CTP-F2 and CTPCgDS-R1 primers (Supplemental Table S1). The CgDHDPS open reading frame (ORF) was amplified from the pUC18 plasmid (above) using CTPCgDS-F1 and CgDS-R2 primers. The amplified fragments were purified and the CTP fragment was fused in-frame to the aminoterminus of CgDHDPS using SOEing PCR (Horton 1995) with gene-specific CTP-F2 and CgDS-R2 primers. All PCR reactions were performed with KAPA $\mathrm{HiFi}^{\mathrm{TM}}$ HotStart DNA polymerase (VWR). Following SalI and NotI restriction digestion, the CTP-CgDHDPS fragment was amplified and cloned into the Gateway enter vector pENTR1A (Life Technologies). The $m C s D H D P S W 53 R$ ORF was amplified by PCR and cloned into the KpnI and NotI sites of pENTR1A. The CTP-CgDHDPS and $m C s D H D P S$ $W 53 R$ ORFs were transferred into the Gateway compatible binary vector pWY190 (Rozwadowski et al. 2008) via LR recombination. The vector uses the Pap85 promoter to direct expression of the transgene and is active during seed maturation and early seed germination in A. thaliana. The Streptomyces species $P A T$ (phosphinothricin acetyltransferase) gene under the control of the constitutive $t C U P 2$ promoter from tobacco (Wu et al. 2003) was used to provide selection for glufosinate (DL-phosphinothricin). The binary vector plasmids were transferred into Agrobacterium tumefaciens GV301 pMP90 and transformation of $C$. sativa DH55 (Kagale et al. 2014) was conducted using the floral dip method (Nguyen et al. 2014). Seed was provided by I. Parkin (Agriculture and Agri-Food Canada). Screening for positive glufosinate-resistant transformants was performed by spraying 6-day-old seedlings with $1.5 \mathrm{~g} \mathrm{~L}^{-1}$ Liberty herbicide (Bayer CropScience). Single-insert homozygous lines were selected using a droplet digital PCR (ddPCR) method (Comte et al. 2017) based on comparison of the copy number of the PAT gene with CsActin2 as an internal reference.
Expression of the transgenes was verified using reverse-transcription PCR (RT-PCR). Total RNA was isolated from 5-10 mg of developing seed (30 days post-anthesis) using a protocol optimized for isolation of RNA from B. napus developing seeds (Sjödahl et al. 1993). RNase-free DNase I (Promega, Madison, WI, USA) was used to eliminate genomic DNA from total RNA prior to gene expression analysis using genespecific primers (Supplemental Table S1) and the SuperScript one-step RT-PCR kit (Life Technologies) as described by Huang et al. (2009). The number of PCR cycles was optimized (30-35 cycles) so that the RT-PCR fell within the linear range. Transcripts from the $C$. sativa $18 S$ ribosomal gene were amplified using Cs18S-F and Cs18S-R primers (Supplemental Table S1) and used as a normalization standard. Three biological replicates were conducted.

Protein homology modeling

The theoretical structure of the $C$. sativa DHDPS isoform CsDHDPS-B6 was constructed based on target-template alignment using ProMod3 Version 1.1.0 within the Swiss-Model server (Biasini et al. 2014). Coordinates that were conserved between the target and the template were copied from the template to the model. Insertions and deletions were remodelled using a fragment library and side chains reconstructed. Finally, the geometry of the model was regularized by using GROMOS96 force field (Guex et al. 2009). The structure of DHDPS-2 from A. thaliana (PDB 4dpp) (Griffin et al. 2012) was identified as the best template by searching the SWISS-MODEL template library (SMTL version 2018-04-25, PDB release 2018-04-20) using BLAST (Camacho et al. 2009) and HHblits (Remmert et al. 2012). The 4dpp structure was determined by X-ray diffraction with a resolution of 2.00 angstroms. 4dpp shared a sequence identity of $90.52 \%$ and had a quaternary structure quality estimate (QSQE) of 0.71 with respect to the generated homology model CsDHDPS-B6. The CsDHDPS-B6 model conformed with the 4dpp template with a global mean quality estimate (GMQE) of 0.80 and a Qmean score of -0.19 (Benkert et al. 2011). Imaging was done using UCSF Chimera (Pettersen et al. 2004). 
Amino acid quantification

Seeds were defatted with n-hexane based on the methods of Troeng (1955) and Barthet and Daun (2004). Mature seeds (2-3 g) were placed in sealed steel tubes with 3 ball bearings and $25 \mathrm{ml}$ of hexanes (Sigma). Samples were ground for $45 \mathrm{~min}$ using an Eberbach shaker followed by vacuum filtration to remove oils and hexane. Defatted meal was air-dried overnight followed by storage at $-20^{\circ} \mathrm{C}$. Total nitrogen content of the defatted meal was determined using a Flash EA 1112 Series N/Protein Analyser (Thermo Scientific). This system uses a dynamic flash combustion system coupled with a gas chromatographic separation system based on the AOAC Official Method 972.43 (1997). Approximately $15 \mathrm{mg}$ of defatted meal from each sample was analyzed in triplicate. The nitrogen to protein conversion factor used was 6.25 (Jones 1931; AACC International Method 46-18.01 1999). Moisture levels in the defatted meal were determined as weight loss upon drying to stability (AACC Method 44-01.01 1999). Approximately $700 \mathrm{mg}$ of defatted camelina meal was dried at $105^{\circ} \mathrm{C}$ for $24 \mathrm{~h}$ in a forced-air oven.

Amino acid profiles were analyzed following the procedure of AOAC Method 994.12 (2005) and Tuan and Philips (1997). Tryptophan was quantified following the method of Nielsen and Hurrell (1985). Microwave digestion methods were modified from Lill et al (2007) and Kabaha et al (2011). Separation and quantification of amino acids was performed using a high-performance liquid chromatography (HPLC) system (Waters Alliance 2695) equipped with a Waters 2475 fluorescence detector with excitation wavelength of $250 \mathrm{~nm}$, emission wavelength of $395 \mathrm{~nm}$ and an AccQ-Tag C18 column for hydrolysate amino acid analysis, $3.9 \times 150 \mathrm{~mm}$ (Waters). Gradient elution was diluted with AccQtag Eluent A buffer, water and acetonitrile. Amino acids were resolved using a multi-step gradient elution with an injection volume of $5 \mu$ l. Response peaks were recorded and analysed with Empower 3 software (Waters Corp.). Pre-column derivatization using AccQ-Fluor reagent (Waters Corp.) was done for all samples, except tryptophan which was diluted with an equivalent ratio of borate buffer and acetonitrile prior to HPLC analysis. For all amino acids except cysteine, methionine and tryptophan, $5 \mathrm{mg}$ of sample (protein basis) was hydrolyzed with $6 \mathrm{M} \mathrm{HCL}$ (Optima grade, Fisher
Scientific) with $1 \%(\mathrm{w} / \mathrm{v})$ phenol in a $10 \mathrm{ml}$ quartz hydrolysis tube using a microwave digester (CEM Discover SPD) set at a ramp time of $5.5 \mathrm{~min}$, hold at $195^{\circ} \mathrm{C}$ for $10 \mathrm{~min}$, maximum pressure of $140 \mathrm{psi}$ and maximum power of $300 \mathrm{~W}$. Hydrolysates were neutralized with sodium hydroxide, filtered through a $0.45 \mu \mathrm{m}$ Phenex RC syringe filter to remove particulates and applied to a Waters Oasis HLB C18 Cartridge for sample cleanup prior to HPLC analysis. Amino acids were eluted from the cartridge with 5\% (v/v) acetonitrile. Flow-through and washes were collected. Cysteine and methionine were determined as cystic acid and methionine sulfone after oxidation with performic acid followed by microwave hydrolysis with $6 \mathrm{M} \mathrm{HCl}$, neutralization and filtration. Tryptophan was determined by hydrolyzing $10 \mathrm{mg}$ of sample (protein basis) in $4.2 \mathrm{M} \mathrm{NaOH}$ in a $10 \mathrm{ml}$ quartz hydrolysis tube with a Teflon liner using a microwave digester (CEM Discover SPD) set at a ramp time of $6.0 \mathrm{~min}$, hold at $215^{\circ} \mathrm{C}$ for $20 \mathrm{~min}$, maximum pressure of $140 \mathrm{psi}$ and maximum power of $300 \mathrm{~W}$. Hydrolyzed samples were neutralized with $\mathrm{HCl}$ and filtered prior to application on a Waters Oasis HLB C18 Cartridge. Tryptophan and 5-methyl tryptophan (internal standard) were eluted from the cartridge with $5 \%(\mathrm{v} / \mathrm{v})$ acetonitrile/5\% (v/v) methanol. The flow-through and washes were collected. Samples were stored at $-20^{\circ} \mathrm{C}$ prior to dilution and HPLC analysis. D,L 2-amino-butyric acid (0.1 mM) and D,L 5-methyl-tryptophan $(0.1 \mathrm{mM})$ (SigmaAldrich) were used as internal standards and added to the sample hydrolysates following acid or base hydrolysis.

\section{Statistical analysis}

For enzyme activity, Levene and Shapiro-Wilk tests were used to assess the homogeneity of variance and the normality at each treatment level. Differences between means of the lysine treatment levels within each line were identified using least squared regression followed by comparison with control (lysine $=0$ $\mu \mathrm{M}$ ) using the Dunnett's test (JMP version 15.0.0; https://www.jmp.com/en_ca/home.html). Lines with probability of less than $0.05 \%$ were considered significant.

Percentages of each amino acid were calculated as a proportion of the total recovered amino acids, adjusted to a recovery of $100 \%$. The Grubbs test was used to 
identify and remove outliers from the technical replicates prior to pooling for each biological replicate. Three biological replicates were used to evaluate the differences between means of all lines, for each amino acid, using standard least squared regression and ranked using the Tukey least significant difference test (LSD). P values less than $0.05 \%$ were considered significant.

Amino acid analysis and nitrogen analysis were performed in triplicate and moisture determination as a single sample. Technical replications presenting a large coefficient of variation $(>10)$ were repeated. Dunnett's test or a one-way ANOVA with a multiple comparison Tukey HSD test were used to identify and rank significant differences.

\section{Results}

\section{Isolation of $C$. sativa DHDPS cDNA}

Two cDNAs encoding CsDHDPS, denoted B4 (Csa16g004020) and B6 (Csa05g092770), were identified and are homoeologues on sub-genomes I and III, respectively. Another CsDHDPS homoeologue (Csa07g004000) is present on sub-genome II, but did not appear among the cDNA clones sequenced. Csa05g092770 is closely linked to a truncated DHDPS gene (Csa05g092750) that may have arisen from a duplication event. Differences between the CsDHDPS $\mathrm{B} 4$ and $\mathrm{B} 6$ proteins included deletion of $\mathrm{R}^{29}$ within the chloroplast targeting peptide at the amino terminus of $\mathrm{B} 4$, and replacement of $\mathrm{K}^{146}$ and $\mathrm{V}^{254}$ in $\mathrm{B} 6$ with $\mathrm{R}^{145}$ and $\mathrm{D}^{253}$ in $\mathrm{B} 4$. A putative chloroplast targeting peptide was predicted to be located at the aminoterminus of all plant DHDPS enzymes (38 aa in $C$. sativa, 29 aa in A. thaliana, 32 aa in N. tabacum, 65 aa in Z. mays) (Fig. 1). Alignment of CsDHDPS B6 with other plant and bacterial DHDPS enzymes showed the plant DHDPSs shared variable identity with their $C$. sativa counterparts ( $94 \%$ with A. thaliana, $75 \%$ with Nicotiana tabacum, $67 \%$ with Zea mays), while the bacterial DHDPSs were more divergent $(27 \%$ with E. coli and $22 \%$ with C. glutamicum).

Residues identified as crucial for catalytic activity of microbial DHDPS were conserved in the $C$. sativa DHDPS, including two residues near the aminoterminus ( $\mathrm{T}^{107}$ and $\mathrm{T}^{108}$ corresponding to $\mathrm{T}^{44}$ and $\mathrm{T}^{45}$ in the E.coli DHDPS, respectively) and eight residues near the carboxy-terminus $\left(\mathrm{Y}^{170}, \mathrm{Y}^{194}, \mathrm{R}^{199}\right.$, $\mathrm{K}^{222}, \mathrm{C}^{224}, \mathrm{G}^{243}, \mathrm{I}^{261}$, and $\mathrm{N}^{300}$ corresponding to $\mathrm{Y}^{107}$, $\mathrm{Y}^{133}, \mathrm{R}^{138}, \mathrm{~K}^{161}, \mathrm{~A}^{163}, \mathrm{G}^{186}, \mathrm{I}^{203}$ and $\mathrm{N}^{248}$ in the $E$ coli DHDPS (Fig. 1). These residues have roles in the formation of the Schiff base (101-118, IPR020624; 194-224, IPR020625; http://www.ebi.ac.uk/interpro/ entry), proton relay during catalysis $\left(\mathrm{Y}^{107}\right.$ and $\left.\mathrm{Y}^{170}\right)$, pyruvate binding $\left(\mathrm{T}^{108}\right.$ and $\left.\mathrm{I}^{261}\right)$ and reaction active sites $\left(\mathrm{Y}^{194}, \mathrm{~K}^{222}\right.$ ) (http://www.uniprot.org/uniprot/ Q9LZX6). Notably, $K^{222}$ (equivalent to $K^{184}$ of the mature CsDHDPS protein) is conserved in the active site and plays a fundamental role in the ping-pong reaction (Atkinson et al. 2012a; Skovpen and Palmer 2013). As importantly, eight conserved residues involved in lysine binding are found in the allosteric regulatory domain (Fig. 1), whereupon binding of lysine leads to active site distortion or impaired dimer formation, resulting in inhibition enzyme activity (Laskowski et al. 2009). Structural modelling of the CsDHDPS indicates it forms a tetramer similar to the A. thaliana DHDPS (Griffin et al. 2012) (Supplemental Figure S1).

\section{Characterization of lysine-insensitive CsDHDPS variants}

Previously, it was shown that a mutation in the $A$. thaliana DHDPS (W53R) resulted in the complete loss of feedback inhibition (Vauterin et al. 2000), while a N80I change in the N. tabacum DHDPS was responsible for lysine over-production (Ghislain et al. 1995). Similarly, the E84K substitution in the Z. mays DHDPS abolished its lysine sensitivity (Shaver et al. 1996). Both the $C$. sativa DHDPS B4 and B6 enzymes were able to complement the $E$. coli dapA mutation on minimal medium in the absence of DAP; however, the strain expressing DHDPS B6 exhibited more robust growth suggesting that it was more active. As such, site-directed mutagenesis was employed to generate similar mutations separately and in combination in the allosteric domain of $C$. sativa DHDPS B6. The three single amino acid changes were designated as CsDHDPS mA (W53R), CsDHDPS mB (N80V) and CsDHDPS mC (E84T) (Fig. 1; Supplemental Figure S1). Numbering of residues was according to E. coli DHDPS.

The auxotrophic E. coli dap ${ }^{-}$strain carrying only the pUC18 vector failed to grow on plates with M9 minimum medium in the absence of DAP; however, 


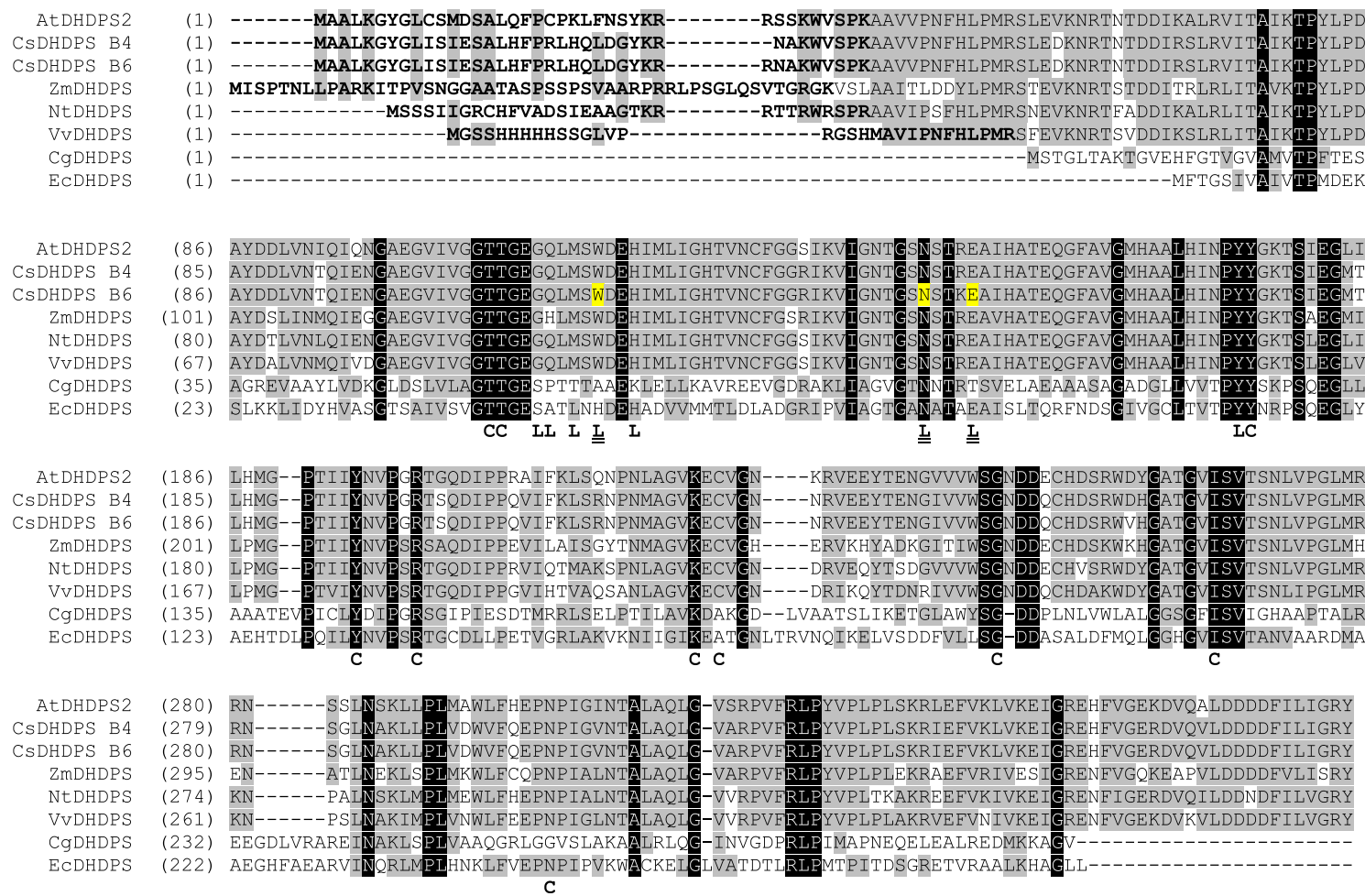

Fig. 1 Conservation between $C$. sativa and other plant and microbial DHDPS enzymes. Amino acid sequence alignment of DHDPSs from A. thaliana (AtDHDPS2, Q9LZX6, 365 aa), $C$. sativa CsDHDPS B4 (Csa16g004020, 364 aa) and CsDHDPS B6 (Csa05g092770, 365 aa), N. tabacum (NtDHDPS, NP_001313049, 359 aa), $Z$. mays (ZmDHDPS, NP_001105425.1, 380 aa), Vitis vinifera (VvDHDPS, PDB 3TUU, 346 aa), C. glutamicum (CgDHDPS, X53993, 301 aa) and E. coli (EcDHDPS, WP_061350668, 292 aa). The predicated chloroplast transit peptides at the $\mathrm{N}$-terminus in the plant enzymes are in bold text. Conserved amino acids involved

strains harbouring plasmids with the CgDHDPS, the wild-type (wt) CsDHDPS or any of the modified CsDHDPS variants grew to varying degrees indicating the modifications did not result in loss of DHDPS activity (Supplemental Figure S2). The addition of DAP restored growth of the dap-pUC18 strain and improved the growth of the lines carrying the wt CsDHDPS or variants. Lines carrying the CgDHDPS or the modified CsDHDPS variants also grew in the presence of the non-metabolizable lysine analogue AEC, indicating they were insensitive to feedback inhibition. Interestingly, AEC failed to completely inhibit the growth of the strain carrying the wt CsDHDPS after extended incubation (14 days) suggesting the endogenous plant enzyme may be partially in catalysis within the catalytic site (C) and those involved in lysine binding in the allosteric (L) sites are shown. The sites of the three mutations introduced into CsDHDPS B6 allosteric site ( $\mathrm{L}$ and highlighted in yellow) are designated as mA (W53R), $\overline{\mathrm{mB}}(\mathrm{N} 80 \mathrm{~V})$ and $\mathrm{mC}(\mathrm{E} 84 \mathrm{~T})$ according the numbering associated with the E. coli DHDPS. Amino acids found in all enzymes (white letters on black background) or amino acids with conserved properties (black letters on grey background) are shown. Alignment performed using the Vector NTI Suite (Life Technologies)

insensitive to lysine inhibition. The CsDHDPS $\mathrm{mA}$ variant appeared to be least sensitive to AEC amongst the variants tested in this assay.

An assessment of the impact of the changes on DHDPS function was conducted by monitoring the growth of E. coli dap- strains expressing the DHDPS variants in the presence of AEC. The E. coli dappUC18 strain failed to grow in the absence of DAP (Fig. 2). The strain expressing the wt CsDHDPS grew on minimal M9 medium, although faster in the presence of $100 \mu \mathrm{M}$ DAP, indicating the CsDHDPS enzyme is functionally equivalent to that encoded by the E. coli dapA locus. Growth of this strain was progressively impaired by increasing AEC concentrations, but was detectable even at the highest 

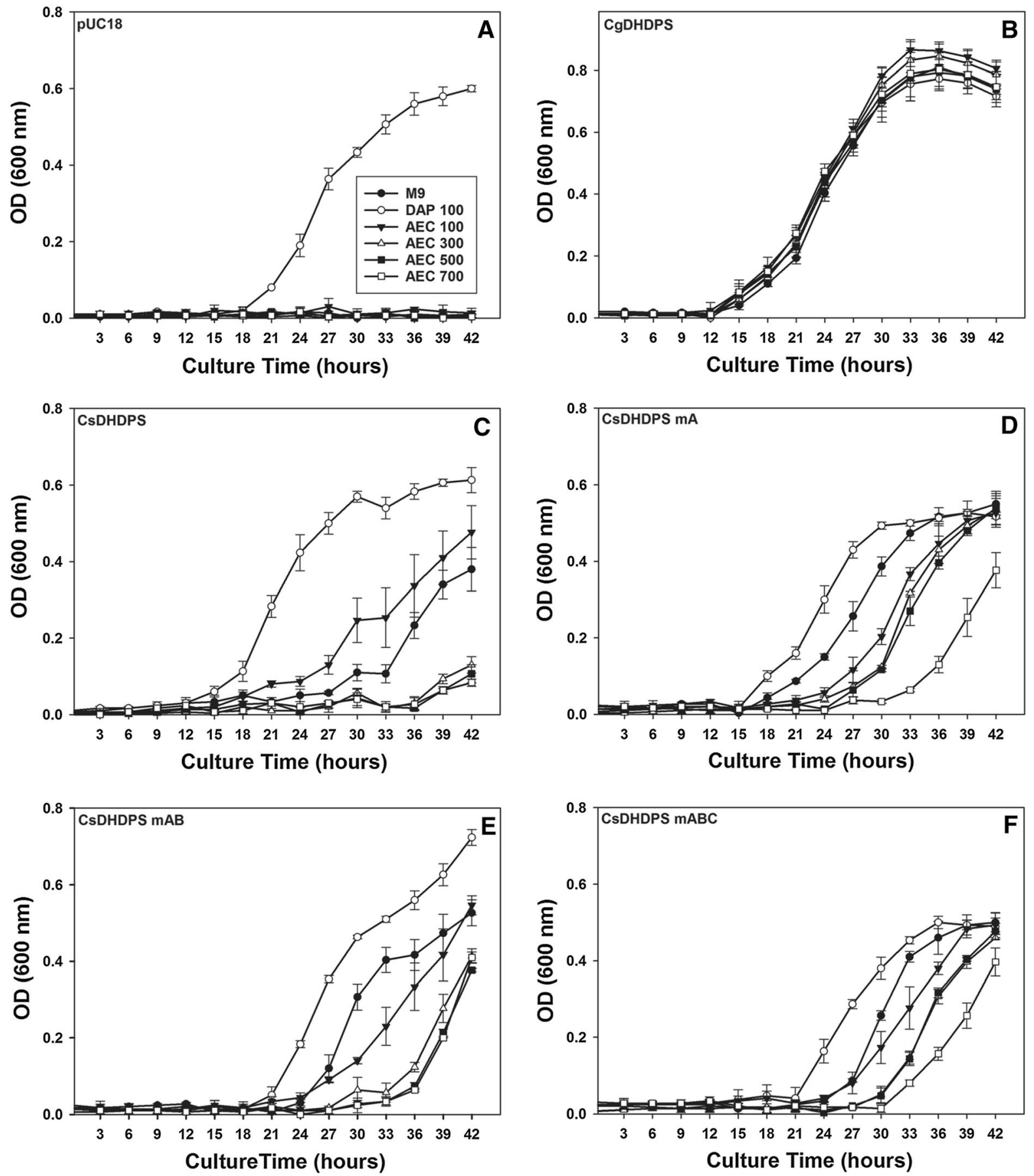

Fig. 2 Growth of E. coli lysine auxotrophic $\left(\right.$ dapA $\left.^{-}\right)$strains harbouring plasmids expressing various DHDPS enzymes. pUC18 = empty vector control (Panel A), CgDHDPS $=C$. glutamicum DHDPS (Panel B), CsDHDPS = wt $C$. sativa DHDPS B6 (Panel C), CsDHDPS mA = W53R mutant (Panel D), CsDHDPS mAB = W53R/N80V double mutant (Panel E),

CsDHDPS $\mathrm{mABC}=\mathrm{W} 53 \mathrm{R} / \mathrm{N} 80 \mathrm{~V} / \mathrm{E} 84 \mathrm{~T}$ triple mutant $($ Panel F). Growth medium included M9 minimal medium (M9), $\mathrm{M} 9+100 \mu \mathrm{M}$ diaminopimelate (DAP 100) or M9 with various concentrations $(\mu \mathrm{M})$ of S-(2-aminoethyl)-L-cysteine (AEC). Errors bars show standard deviation $(n=3)$ 
concentration suggesting that CsDHDPS may be partially insensitive to lysine. Strains expressing the CsDHDPS $\mathrm{mA}, \mathrm{mB}$ or $\mathrm{mC}$ variants exhibited better growth than that expressing the wt CsDHDPS with only a short delay in the onset of the exponential phase and growth rates similar to that on M9 medium alone thereafter. The growth of the strain expressing CgDHDPS was not affected by any of the AEC concentrations tested. The time required for cultures to reach the same optical density $\left(\mathrm{OD}_{600}=0.3\right)$ was also calculated to assess the in vivo sensitivity of modified DHDPS variants to AEC (Supplemental Table S2.1). In the absence of AEC and with the inclusion of DAP, the variants grew normally and reached similar culture densities $\left(\mathrm{OD}_{600}=0.3\right)$ within $22-28 \mathrm{~h}$. AEC addition increased the time for the variant cultures to reach the same density; however, strains expressing the CgDHDPS or CsDHDPS $\mathrm{mA}$ took the least time, 21.5-22 $\mathrm{h}$ and 31.5-40 $\mathrm{h}$, respectively, indicating that these enzymes are the least sensitive to AEC or lysine. Growth rate during the exponential phase decreased in the strain carrying the wt CsDHDPS with increasing AEC concentration; however, growth rates were similar in the lines carrying the CsDHDPS variants once the exponential phase had begun (Supplemental Table S2.2).

In vitro enzyme assays were conducted to compare the degree to which the CsDHDPS variants were insensitive to lysine (Fig. 3). The specific activity of the single mutation $\mathrm{mA}, \mathrm{mB}$ and $\mathrm{mC}$ variants was higher than that of the wt CsDHDPS and $\mathrm{mA}$ was comparable to that of CgDHDPS. The mAB combination significantly reduced activity, while the $\mathrm{mABC}$ combination displayed activity comparable to the wt CsDHDPS enzyme. The wt CsDHDPS was highly sensitive to lysine with only $20 \%$ of the activity remaining at $25 \mu \mathrm{M}$ free lysine; the lowest concentration tested. A basal level of activity (ca. 10\%) remained even at higher lysine concentrations which supports the tenet that the CsDHDPS enzyme may be partially insensitive to lysine. The $\mathrm{mA}$ CsDHDPS variant was the most insensitive to lysine inhibition with activity being unaffected even at the highest concentrations tested, $1000 \mu \mathrm{M}$ free lysine, suggesting a critical role of the W53R substitution in lowering the affinity of the allosteric site for lysine. The $\mathrm{mB}$ and $\mathrm{mC}$ variants were more sensitive to lysine than the $\mathrm{mA}$ variant with activity diminishing as free lysine concentration increased and with less than $20 \%$ remaining
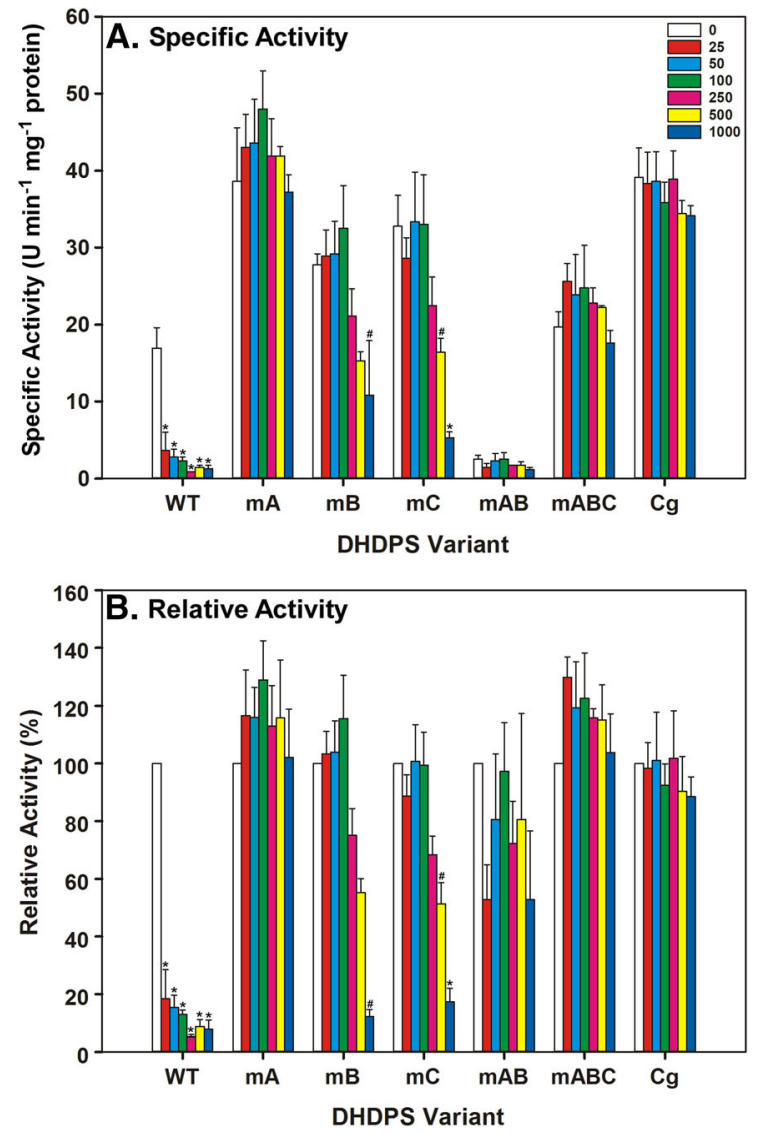

Fig. 3 Sensitivity of various DHDPS enzymes to lysine feedback inhibition. Panel A: Specific activity of protein extracts from $E$. coli lysine auxotrophic (dapA-) strains harbouring plasmids expressing various DHDPS enzymes. C. sativa DHDPS B6 (Cs), CsDHDPS W53R mutant (mA), CsDHDPS N80V mutant (mB), CsDHDPS E84T mutant (mC), CsDHDPS W53R/N80V double mutant (mAB), CsDHDPS W53R/N80V/E84T triple mutant (mABC), $C$. glutamicum DHDPS $(\mathrm{Cg})$. Panel B: DHDPS activity relative to activity in the absence of lysine. Lysine concentrations are in $\mu \mathrm{M}$. Values that were significantly different from the control $(0$ lysine) within each group are indicated by an asterisk (*, $P \leq 0.05$ ) or pound sign (\#, $P \leq 0.10$ ) according to Dunnett's test. Error bars indicate standard deviation $(n=3)$

at the $1000 \mu \mathrm{M}$ lysine level. The double mutant $(\mathrm{mAB})$ and the triple mutant $(\mathrm{mABC})$ were less sensitive to lysine with the latter being comparable to the $\mathrm{mA}$ variant. The CgDHDPS was insensitive to lysine at all concentrations tested. 
Evaluation of transgenic $C$. sativa lines expressing $C g D H D P S$ or CsDHDPS $m A$

The most active and lysine-insensitive DHDPS enzymes (CgDHDPS and CsDHDPS $\mathrm{mA}$ ) based on the in vitro and in vivo assays were selected for expression in $C$. sativa seeds. Three independent homozygous single-transgene lines expressing $C g D H D P S$ and four expressing CsDHDPS $m A$ (Fig. 4) were used to evaluate phenotypic changes and amino acid content.

The PAP85 promoter is active during seed maturation and the early phase of seedling establishment (Rozwadowski et al. 2008). We confirmed that the CgDHDPS and CsDHDPS mA enzymes were active during this time by germinating seeds and growing the seedlings in the presence of AEC (Fig. 4). In the wt DH55 line, radicles initially emerged from the seed, but further growth was suspended and seedlings
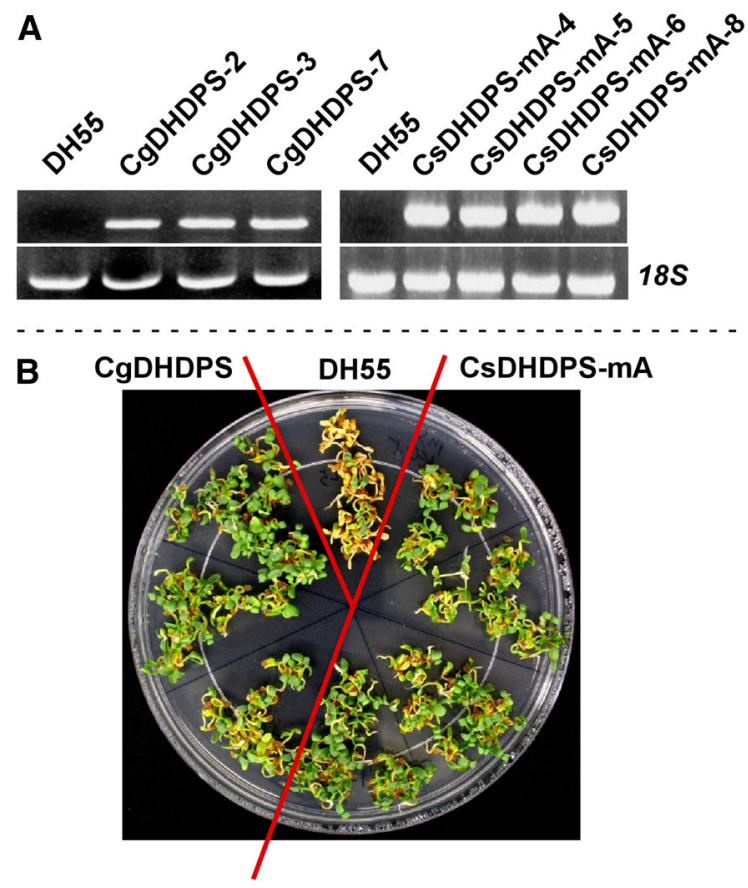

Fig. 4 Characterization of transgenic $C$. sativa lines expressing genes encoding $C$. glutamicum DHDPS or the $C$. sativa DHDPS W53R mutant mA. Panel A: Gene expression as determined by RT-PCR in C. sativa DH55 (untransformed control) and several independent, single transgene insert, homozygous lines expressing $C g D H D P S$ or $C s D H D P S m A$. Expression of $C$. sativa $18 \mathrm{~S}$ ribosomal RNA was used as a control for total RNA input. Panel B: Growth of seedlings on $0.5 \times$ MS-sucrose plates with $1.5 \mathrm{mM}$ AEC became chlorotic after 7 days and necrotic (brown) after 10 days. In contrast, transgenic seedlings expressing $C g D H D P S$ or $C s D H D P S m A$ were much lesser sensitive to AEC.

Some alterations in plant growth and seed characteristics were noted when the CgDHDPS and CsDHDPS $\mathrm{mA}$ lines were grown in soil under controlled conditions. Seedlings of some of the transgenic lines were smaller and slower to establish relative to DH55 (Supplemental Figure S3), but only minor variations in plant height and flowering time were observed among the independent transgenic lines (Fig. 5). The CgDHDPS Cg-7 line was delayed in flowering (37.25 d), whereas the CsDHDPS mA-4 line flowered earlier (31.75 d) compared to DH55 (34.3 d). Pod maturation was not significantly delayed in the transgenic lines, except for the CgDHDPS Cg-2 line (Fig. 5). Total seed weight (yield) was reduced in all three CgDHDPS lines with total production only $42-71 \%$ of the DH55 control. Seed production was less affected in the CsDHDSP $\mathrm{mA}$ lines, which showed yields ranging from 70-98\% that of DH55 (Fig. 5) and only one (mA-6) had significantly reduced total seed yield. None of the lines exhibited significantly different hundred seed weight compared to the DH55 control.

Alteration of lysine and other amino acids in seed

Meal amino acid profile is governed mainly by the seed protein fraction, while free amino acids account for only $1-10 \%$ of the total amino acid pool. Therefore, the total (free and protein-associated) amino acid profiles were determined in the transgenic seed. All of the lines expressing $C g D H D P S$ had significantly higher levels of lysine (5.84-6.3\%) than the DH55 control $(5.14 \pm 0.06 \% ; 26.74 \pm 0.22 \mathrm{mg}$ per g dry defatted meal), while three of the four lines expressing CsDHDPS $m A$ lines had significantly greater levels of lysine (5.57-5.82\%) (Supplemental Table S3). This represented a 13.6 to $22.6 \%$ increase in lysine with CgDHDPS and 7.6 to $13.2 \%$ increase with CsDHDPS $\mathrm{mA}$ compared to the DH55 control. Interestingly, lines that accumulated lysine at $13 \%$ or more above the DH55 level (CgDHDPS-2, -3, -7; CsDHDPS mA-6) also had reduced total seed yield (Fig. 5).

Most monogastric animals are unable to synthesize histidine, isoleucine, leucine, lysine, methionine, phenylalanine, threonine, tryptophan and valine, and 
Growth Characteristics
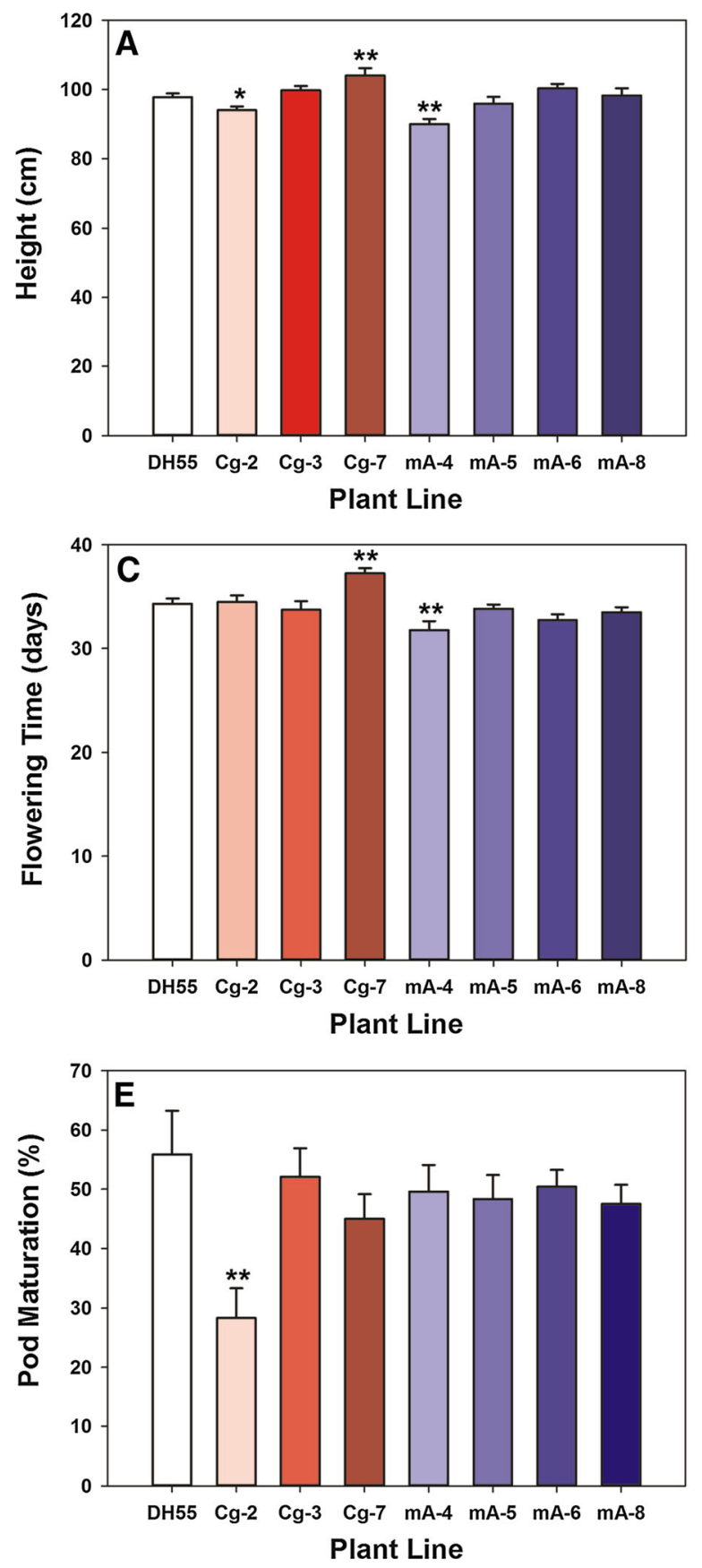

Fig. 5 Comparison of growth (Panels A, C, E) and seed characteristics (Panels B, D, F) of C. sativa DH55 (untransformed control) to several independent, single transgene insert, homozygous lines expressing genes encoding C. glutamicum DHDPS (Cg) or the C. sativa W53R DHDPS mutant mA. Plant height was measured at 62 days, flowering time was recorded
Seed Characteristics
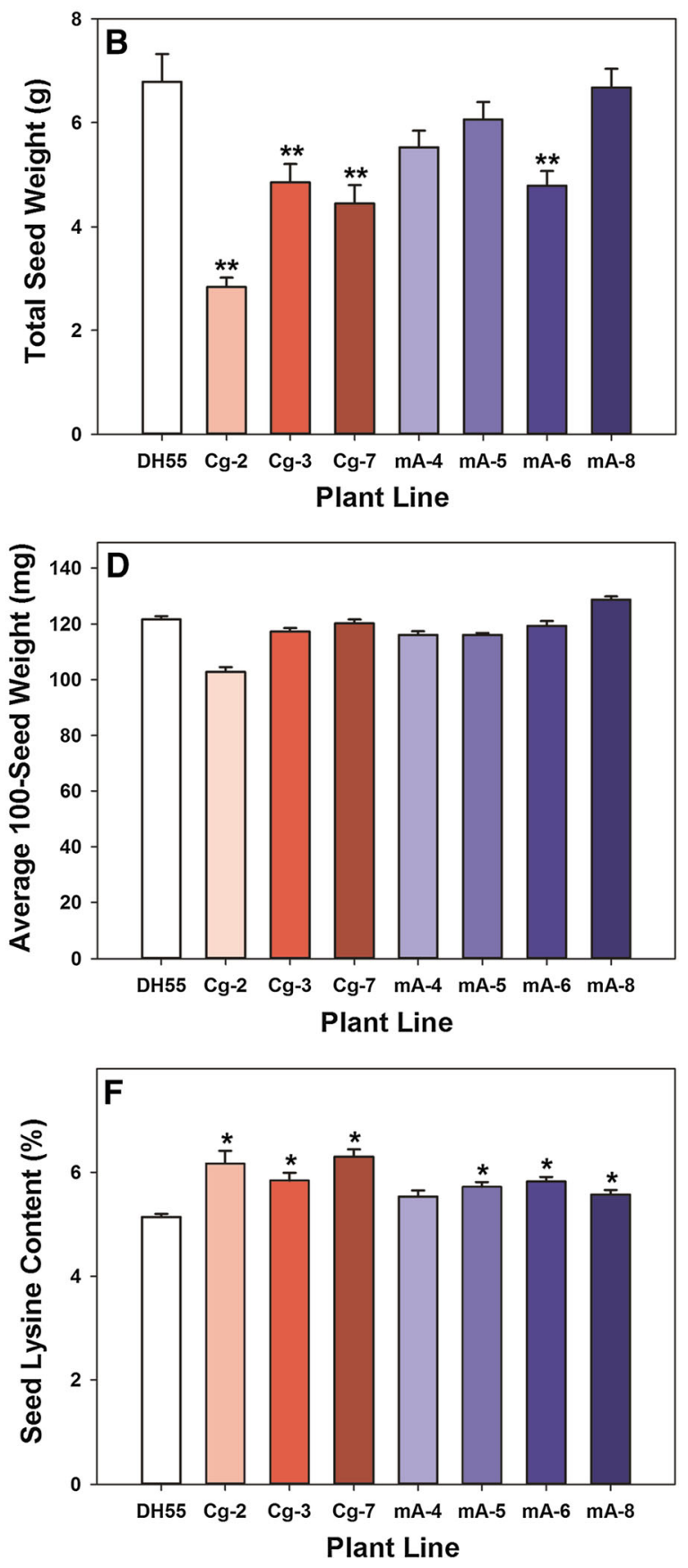

when first flower opened, pod maturation was determined at 77 days. Values that were significantly different from the control (DH55) are indicated by a single $(P \leq 0.05)$ or double $(P \leq 0.01)$ asterisk (one-way ANOVA and Tukey HST test). Error bars indicate standard deviation $(\mathrm{n}=3)$ 
must acquire them from their diets, hence these are referred to as essential amino acids. As such, the impact of increasing lysine content on the levels of these and other amino acids was also evaluated in the meal. In addition to lysine, histidine levels also increased in the transgenic seed by $3.7-6 \%$, while the level of the non-essential amino acid alanine increased in CgDHDPS-2 (4\%) and CgDHDPS-7 (3\%), and the CsDHDPS mA-4 (2.8\%) lines (Supplemental Table S3). In contrast, significant decreases were noted in tryptophan in CgDHDPS-3 (13.6\%), CsDHDPS-mA-5 (12\%) and CsDHDPS-mA-6 (12\%). Reductions in tryptophan in other lines exceeded $7 \%$, but were not considered statistically different from DH55. The sulphur-containing cysteic acid was significantly reduced in the CgDHDPS-3 (10.6\%), CgDHDPS-7 (10\%), CsDHDPS mA-4 (13.6\%), CsDHDPS-mA-5 (10.9\%) and CsDHDPS mA-4 (10.9\%) lines. Arginine was also significantly reduced, but to a more moderate extent in CgDHDPS-3 (8\%), CsDHDPS-mA-4 (3\%), CsDHDPS-mA-5 (5\%), CsDHDPS-mA-6 (6\%) and CsDHDPS-mA-8 (6\%). Lastly, a reduction in glutamic acid content was observed in CgDHDPS-2 (3.4\%), but not in other transgenic lines.

\section{Discussion}

Cold pressing of camelina seed results in a meal that is rich in protein and residual oil. Similar to other Brassicaceae, the meal contains anti-nutritional/antipalative compounds such as glucosinolates, phytic acid and sinapine; however, it has been subjected to comparatively limited breeding efforts to address reducing these seed constituents. Even in its current form, camelina meal can be included in poultry (Kakani et al. 2012), swine (Kahindi et al. 2014), beef (Cappellozza et al. 2012; Colombini et al. 2014) and aquaculture (Hixon and Parish 2014; Hixon et al. 2014, Hixon et al. 2016a, 2016b) diets. Most plantbased diets are limiting in one or more essential amino acids, such as methionine and lysine (Zubr 2003; Galili et al. 2016), although camelina meal has a somewhat better constitution. In this study, a bacterial and an engineered isoform of $C$. sativa DHDPS were used to enhance lysine levels incorporated into protein in camelina meal.
Plant DHDPS enzymes are generally highly sensitive to lysine feedback-inhibition; however, isoforms from A. thaliana (Vauterin et al. 2000), N. tabacum (Ghislain et al. 1995) and Z. mays (Shaver et al. 1996) have been identified in which single point mutations greatly alter sensitivity to lysine. When engineered into $C$. sativa DHDPS, each of these mutations rendered the enzymes less sensitive to lysine feedback inhibition to varying degrees. $\mathrm{W}^{53}$ is present in the allosteric site and is conserved among plants, but not bacterial, DHDPS enzymes. It functions in the positioning of helix $\alpha 2$ similar to $\mathrm{H}^{53}$ in $E$. coli DHDPS (Blickling et al. 1997b). In the current study, introduction of a $\mathrm{W}^{53} \mathrm{R}$ mutation in $C$. sativa DHDPS resulted in a near complete loss of feedback inhibition while coincidently increasing its specific activity. In fact, this mutation resulted in a level of lysine insensitivity similar to that of the C. glutamicum DHDPS.

Feedback inhibition of DHDPS is mediated by the interaction of lysine with moieties within an allosteric site, which subsequently alters the conformation of the active site. The $C$. glutamicum DHDPS is impervious to lysine-feedback inhibition (Rice et al. 2008), while the E. coli DHDPS is partially insensitive to lysine, although the precise differences responsible for this are not fully understood (Geng et al. 2013). Comparison of lysine-bound and lysine-free grape vine DHDPS structures revealed a conformational shift within the allosteric site $\left(\operatorname{Trp}^{78}\right)$ and important catalytic residues within the active site $\left(\mathrm{Tyr}^{131}\right.$, $\mathrm{Tyr}^{132}$ ) upon lysine binding (Atkinson et al. 2013). Molecular dynamic simulations suggested the rotation of $\mathrm{Tyr}^{132}$ could attenuate proton relay through the catalytic triad in the presence of lysine. There was some indication of molecular or structural interplay between residues within the $C$. sativa DHDPS allosteric site as coupling of the $\mathrm{W}^{53} \mathrm{R}$ mutation with the $\mathrm{N}^{80} \mathrm{~V}$ mutation decreased lysine sensitivity compared to $\mathrm{N}^{80} \mathrm{~V}$ alone, but not to the level observed with the $\mathrm{W}^{53} \mathrm{R}$ mutation alone. However, when the $\mathrm{E}^{84} \mathrm{~T}$ mutation was introduced into this double mutant to create a triple mutant, lysine sensitivity was similar to the $\mathrm{W}^{53} \mathrm{R}$ mutation alone or $C$. glutamicum DHDPS.

Each of the mutations increased lysine insensitivity, but also affected the activity of the enzyme when introduced alone. The same observation was made with C. glutamicum DHDPS isoforms in which the 
allosteric site had been altered to resemble that of E. coli (Geng et al. 2013) indicating even in the absence of lysine, residues within the allosteric site and their interaction impact the conformation of the active site. In support of this notion was the observation the specific activity of the CsDHDPS double mutant $\left(\mathrm{W}^{53} \mathrm{R} / \mathrm{N}^{80} \mathrm{~V}\right)$ was reduced relative to the wild type enzyme; however, activity was restored in the triple mutant $\left(\mathrm{W}^{53} \mathrm{R} / \mathrm{N}^{80} \mathrm{~V} / \mathrm{E}^{84} \mathrm{~T}\right)$. This is in agreement with structural studies indicating $\mathrm{N}^{80}$ is connected to $\mathrm{R}^{138}$ in the active site, therefore, any perturbation could have an immediate and profound impact on activity (Blickling et al. 1997a, 1997b).

In this study, the introduction of feedback-insensitive isoforms of DHDPS resulted in an increase in total seed lysine. While strategies to deregulate lysine biosynthesis or prevent its degradation lead to large increases in free lysine in seeds, this does not necessarily translate to equivalent increases in total lysine (free and incorporated into protein). For example, expression of CordapA in B. napus seeds led to a 100 -fold increase in free lysine, but only a two-fold $(100 \%)$ increase in total lysine (Falco et al. 1995) which is more than, but at least comparable to, that observed in the current study with $C$. sativa (22.6\%). Furthermore, the amount of any free amino acid is very low compared to that incorporated into protein; therefore, reporting only increases in the free form can be misleading. Incorporation of free lysine into protein is dependent on the availability of uncharged lysyltransfer RNAs and mRNA with corresponding codons. As such, further increases in total lysine accumulation could be achieved through the introduction of highlysine sink proteins (Yu et al. 2005; Chang et al. 2015; Liu et al. 2016; Jiang et al. 2016) or the manipulation of seed protein composition (Kohno-Murase et al. 1995; Kim et al. 2013; Schmidt et al. 2016) to favour accumulation of protein with higher lysine contents. It should be noted that lysine, aspartate, glutamine and glutamate constitute a central regulatory metabolic network in plant amino acid metabolism (Lam et al. 1995; Zhu and Galili 2003); therefore, directing metabolic flux toward lysine synthesis may impact other pathways. Moreover, glutamate is a major product of the lysine catabolism pathway (Galili et al. 2001) and its homeostasis is strictly regulated because of its vital role in signaling (Forde and Lea 2007). In the current study, the elevated lysine level in the transgenic $C$. sativa seeds expressing $C g D H D P S$ was correlated with lower levels of glutamate, although no significant effect on aspartate was observed. A similar observation was made in $A$. thaliana seeds where lysine over-accumulation was positively correlated with glutamine and asparagine, but negatively correlated with aspartate and glutamate (Zhu and Galili 2004). Hence, in any effort to enhance the level of lysine or other essential amino acid it is important to evaluate the overall impact on amino acid composition to ensure that it remains balanced and suitable for the desired application.

Increased accumulation of lysine in $C$. sativa seeds impacted seed production. In plants, lysine synthesis and catabolism are highly regulated, which is in keeping with the important role of lysine in maintaining proper growth and development (Galili 1995; Azevedo and Lea 2001). High levels of free lysine in N. tobacum are associated with loss of apical dominance, delayed flowering and senescence, partial sterility and abnormal leaf appearance (Frankard et al. 1992; Shaul and Galili 1993). In A. thaliana, constitutively expressing a bacterial DHDPS with the CaMV $35 S$ promoter in an $l k r / s d h$ mutant background caused a dwarf phenotype (Zhu and Galili 2004). Deficiencies of several TCA cycle metabolites, such as fumarate and citrate, leading to energy stress may be responsible for impaired seed germination in this line (Galili 2011; Angelovici et al. 2011). These deleterious effects may be alleviated using a seed-specific promoter to direct expression of the DHDPS transgene (Falco et al. 1995). In light of this, the PAP85 promoter was used in the current study as it is active only during seed maturation and the early phase of seedling growth (Rozwadowski et al. 2008). For the most part, seed germination and early seedling development were not impacted in most of the transgenic lines. However, seed yield was reduced; more so in lines expressing $C g D H D P S$ and less so in lines expressing CsDHDPS $m A$. The $C g D H D P S$ lines also exhibited higher levels of total seed lysine accumulation and it is possible that this had a deleterious effect on seed development via one or more of the mechanisms described above. The impact on seed yield has not been reported in other similar studies; however, wrinkled seed appearance and poor germination were correlated with higher levels of lysine in soybean lines expressing CgDHDPS (Falco et al. 1995). This suggests that there may be practical limits to which lysine levels can be increased in seeds. Based on the 
range of lysine levels in the transgenic lines and the correlation with the degree of negative impact on growth and development, the practical limit for lysine accumulation in C. sativa seed is about a $10 \%$ increase above that in the DH55 line (26.74 $\pm 0.22 \mathrm{mg}$ per $\mathrm{g}$ dry defatted meal) used in these experiments. However, it should be noted that we measured total (free and protein-incorporated) lysine as this is an accurate measure of lysine availability. If the negative effects are associated with elevated levels of free lysine, it is possible that inclusion of a more subsuming sink (e.g. a high lysine protein) may alleviate some of these.

In summary, this study demonstrated it is possible to engineer lysine feedback-inhibition insensitive isoforms of $C$. sativa DHDPS resulting in an increase in protein-incorporated lysine in seed. Notably, this study also revealed that individual mutations and combinations of mutations must be examined within the context of the enzyme under study to generate variants that are not only insensitive to lysine, but remain highly active. With the ability to edit genes directly within the $C$. sativa genome (Lyzenga et al. 2019), it may be possible to re-engineer one or more of the endogenous CsDHDPS paralogues to confer these properties.

Acknowledgements Funding was provided by Agriculture \& Agri-Food Canada through the Canadian Crop Genomics Initiative and the Global Institute for Food Security. L-aspartic- $\beta$-semi-aldehyde (L-ASA) was synthesized by Dr. David Palmer, Department of Chemistry, University of Saskatchewan, Saskatoon, SK, Canada (dave.palmer@usask.ca).

Open Access This article is licensed under a Creative Commons Attribution 4.0 International License, which permits use, sharing, adaptation, distribution and reproduction in any medium or format, as long as you give appropriate credit to the original author(s) and the source, provide a link to the Creative Commons licence, and indicate if changes were made. The images or other third party material in this article are included in the article's Creative Commons licence, unless indicated otherwise in a credit line to the material. If material is not included in the article's Creative Commons licence and your intended use is not permitted by statutory regulation or exceeds the permitted use, you will need to obtain permission directly from the copyright holder. To view a copy of this licence, visit http://creativecommons.org/licenses/by/4.0/.

\section{References}

AACC International Method 44-01.01 (1999) Calculation of percent moisture. In: Approved methods of analysis, 11th Edn (AACC International), St. Paul, MN, USA. https://doi. org/10.1094/AACCIntMethod-44-01.01

AACC International Method 46-18.01 (1999) Crude protein, calculated from percentage of total nitrogen in feeds and feedstuffs. In: Approved methods of analysis, 11th Edn (AACC International), St. Paul, MN, USA. https://doi.org/ 10.1094/AACCIntMethod-46-18.01

AOAC Official Method SMPR 994.12 (2005) Amino acids in feeds: Performic acid oxidation with acid hydrolysissodium metabisulfite method. In: Official methods of analysis of AOAC international, 18th Edn (AOAC International), Gaithersburg, MD, USA

AOAC Official Method 972.43 (1997) Microchemical determination of carbon, hydrogen, and nitrogen, automated method. In: Official methods of analysis of AOAC international, 16th Edn (AOAC International), Arlington, VA, US

Angelovici R, Fait A, Fernie AR, Galili G (2011) A seed highlysine trait is negatively associated with the TCA cycle and slows down Arabidopsis seed germination. New Phytol 189:148-159

Atkinson SC, Dogovski C, Downton MT, Pearce FG, Reboul CF, Buckle AM, Gerrard JA, Dobson RCJ, Wagner J, Perugini MA (2012) Crystal, solution and in silico structural studies of dihydrodipicolinate synthase from the common grapevine. PLoS One 7:e38318

Atkinson SC, Dogovski C, Dobson RC, Perugini MA (2012b) Cloning, expression, purification and crystallization of dihydrodipicolinate synthase from Agrobacterium tumefaciens. Acta Crystallogr Sect F Struct Biol Cryst Commun 68:1040-1047

Atkinson SC, Dogovski C, Downton MT, Czabotar PE, Dobson RC, Gerrard JA, Wagner J, Perugini MA (2013) Structural, kinetic and computational investigation of Vitis vinifera DHDPS reveals new insight into the mechanism of lysinemediated allosteric inhibition. Plant Mol Biol 81:431-446

Atkinson SC, Hor L, Dogovski C, Dobson RC, Perugini MA (2014) Identification of the bona fide DHDPS from a common plant pathogen. Proteins 82:1869-1883

Azevedo RA, Lea PJ (2001) Lysine metabolism in higher plants. Amino Acids 20:261-279

Bansal S, Durrett TP (2016) Camelina sativa: An ideal platform for the metabolic engineering and field production of industrial lipids. Biochimie 120:9-16

Barthet VJ, Daun JK (2004) Oil content analysis: myths and reality. In: Luthria DL (ed) Oil extraction and analysis: critical issues and comparative studies. AOCS Press, Arlington, pp 100-117

Benkert P, Biasini M, Schwede T (2011) Toward the estimation of the absolute quality of individual protein structure models. Bioinformatics 27:343-350

Biasini M, Bienert S, Waterhouse A, Arnold K, Studer G, Schmidt T, Kiefer F, Cassarino TG, Bertoni M, Bordoli L, Schwede T (2014) SWISS-MODEL: modelling protein tertiary and quaternary structure using evolutionary information. Nucl Acids Res 42:W252-W258 
Blickling S, Renner C, Laber B, Pohlenz HD, Holak TA, Huber R (1997a) Reaction mechanism of Escherichia coli dihydrodipicolinate synthase investigated by X-ray crystallography and NMR spectroscopy. Biochemistry 36:24-33

Blickling S, Beisel HG, Bozic D, Knäblein J, Laber B, Huber R (1997b) Structure of dihydrodipicolinate synthase of $\mathrm{Ni}$ cotiana sylvestris reveals novel quaternary structure. J Mol Biol 274:608-621

Brinegar MJ, Williams HH, Ferris FH, Loosli JK, Maynard LA (1950) The lysine requirements for the growth of swine. J Nutr 42:129-138

Camacho C, Coulouris G, Avagyan V, Ma N, Papadopoulos J, Bealer K, Madden TL (2009) BLAST+: architecture and applications. BMC Bioinformatics 10:421-430

Cappellozza BI, Cooke RF, Bohnert DW, Cherian G, Carroll JA (2012) Effects of camelina meal supplementation on ruminal forage degradability, performance, and physiological responses of beef cattle. J Anim Sci 90:4042-4054

Chang Y, She E, Wen L, Yu J, Zhu D, Zhao Q (2015) Seedspecific expression of the Arabidopsis AtMAP18 gene increases both lysine and total protein content in maize. PLoS One 10:e0142952

Colombini S, Broderick GA, Galasso I, Martinelli T, Rapetti L, Russo R, Reggiani R (2014) Evaluation of Camelina sativa (L.) Crantz meal as an alternative protein source in ruminant rations. J Sci Food Agric 94:736-743

Comte A, Gräfenhan T, Links MG, Hemmingsen SM, Dumonceaux TJ (2017) Quantitative molecular diagnostic assays of grain washes for Claviceps purpurea are correlated with visual determinations of ergot contamination. PLoS One 12:e173495

Dereppe C, Bold G, Ghisalba O, Ebert E, Schar HP (1992) Purification and characterization of dihydrodipicolinate synthase from pea. Plant Physiol 98:813-821

Falco SC, Guida T, Locke M, Mauvais J, Sanders C, Ward RT, Webber P (1995) Transgenic canola and soybean seeds with increased lysine. Biotechnology 13:577-582

Forde BG, Lea PJ (2007) Glutamate in plants: metabolism, regulation, and signalling. $\mathrm{J}$ Exp Bot 58:2339-2358

Frankard V, Ghislain M, Jacobs M (1992) Two feedback-insensitive enzymes of the aspartate pathway in Nicotiana sylvestris. Plant Physiol 99:1285-1293

Frisch DA, Gengenbach BG, Tommey AM, Sellner JM, Somers DA, Myers DE (1991) Isolation and characterization of dihydrodipicolinate synthase from maize. Plant Physiol 96:444-452

Erzeel E, Van Bochaute P, Thu TT, Angenon G (2013) Medicago truncatula dihydrodipicolinate synthase (DHDPS) enzymes display novel regulatory properties. Plant Mol Biol 81:401-415

Frizzi A, Huang S, Gilbertson LA, Armstrong TA, Luethy MH, Malvar TM (2008) Modifying lysine biosynthesis and catabolism in corn with a single bifunctional expression/ silencing transgene cassette. Plant Biotechnol J 6:13-21

Galili G (1995) Regulation of lysine and threonine synthesis. Plant Cell 7:899-906

Galili G, Tang G, Zhu X, Gakiere B (2001) Lysine catabolism: a stress and development super-regulated metabolic pathway. Curr Opin Plant Biol 4:261-266
Galili G (2002) New insights into the regulation and functional significance of lysine metabolism in plants. Annu Rev Plant Biol 53:27-43

Galili G (2011) The aspartate-family pathway of plants: linking production of essential amino acids with energy and stress regulation. Plant Signal Behav 6:192-195

Galili G, Amir R, Fernie AR (2016) The regulation of essential amino acid synthesis and accumulation in plants. Annu Rev Plant Biol 67:153-178

Geng F, Chen Z, Zheng P, Sun J, Zeng AP (2013) Exploring the allosteric mechanism of dihydrodipicolinate synthase by reverse engineering of the allosteric inhibitor binding sites and its application for lysine production. Appl Microbiol Biotechnol 97:1963-1971

Ghislain M, Frankard V, Jacobs M (1990) Dihydrodipicolinate synthase of Nicotiana sylvestris, a chloroplast-localized enzyme of the lysine pathway. Planta 180:480-486

Ghislain M, Frankard V, Jacobs M (1995) A dinucleotide mutation in dihydrodipicolinate synthase of Nicotiana sylvestris leads to lysine overproduction. Plant J 8:733-743

Gibbon BC, Larkins BA (2005) Molecular genetic approaches to developing quality protein maize. Trends Genet 21:227-233

Griffin MDW, Billakanti JM, Wason A, Keller S, Mertens HDT, Atkinson SC, Dobson RCJ, Perugini MA, Gerrard JA, Pearce FG (2012) Characterization of the first enzymes committed to lysine biosynthesis in Arabidopsis thaliana. PLoS One 7:e40318

Guex N, Peitsch MC, Schwede T (2009) Automated comparative protein structure modeling with SWISS-MODEL and Swiss-PdbViewer: a historical perspective. Electrophoresis 30:S162-S173

Hixson SM, Parrish CC (2014) Substitution of fish oil with camelina oil and inclusion of camelina meal in diets fed to Atlantic cod (Gadus morhua) and their effects on growth, tissue lipid classes, and fatty acids. J Anim Sci 92:1055-1067

Hixson SM, Parrish CC, Anderson DM (2014) Full substitution of fish oil with camelina (Camelina sativa) oil, with partial substitution of fish meal with camelina meal, in diets for farmed Atlantic salmon (Salmo salar) and its effect on tissue lipids and sensory quality. Food Chem 157:51-61

Hixson SM, Parrish CC, Wells JS, Winkowski EM, Anderson DM (2016a) Inclusion of camelina meal as a protein source in diets for farmed Atlantic cod Gadus morhua. Aqua Res 47:2607-2622

Hixson SM, Parrish CC, Wells JS, Winkowski EM, Anderson DM, Bullerwell CN (2016b) Inclusion of camelina meal as a protein source in diets for farmed salmonids. Aqua Nutr 22:615-630

Horton RM (1995) PCR-mediated recombination and mutagenesis. SOEing together tailor-made. Genes Mol Biotechnol 3:93-99

Huang S, Kruger DE, Frizzi A, D’Ordine RL, Florida CA, Adams WR, Brown WE, Luethy MH (2005) High-lysine corn produced by the combination of enhanced lysine biosynthesis and reduced zein accumulation. Plant Biotechnol J 3:555-569

Huang J, Bhinu VS, Li X, Dallal Bashi Z, Zhou R, Hannoufa A (2009) Pleiotropic changes in Arabidopsis f5h and sct 
mutants revealed by large-scale gene expression and metabolite analysis. Planta 230:1057-1069

Jander G, Joshi V (2010) Recent progress in deciphering the biosynthesis of aspartate-derived amino acids in plants. Mol Plant 3:54-65

Jiang SY, Ma A, Xie L, Ramachandran S (2016) Improving protein content and quality by over-expressing artificially synthetic fusion proteins with high lysine and threonine constituent in rice plants. Sci Rep 6:34427

Jones DB (1931) Factors for converting percentages of nitrogen in foods and feeds into percentages of protein. Washington, DC, US Department of Agriculture Circulation 183:1-21

Kabaha K, Taralp A, Cakmak I, Ozturk L (2011) Accelerated hydrolysis method to estimate the amino acid content of wheat (Triticum durum Desf.) flour using microwave irradiation. J Agric Food Chem 59:2958-2965

Kagale S, Koh C, Nixon J, Bollina V, Clarke WE, Tuteja R, Spillane C, Robinson SJ, Links MG, Clarke C, Higgins EE, Huebert T, Sharpe AG, Parkin IA (2014) The emerging biofuel crop Camelina sativa retains a highly undifferentiated hexaploid genome structure. Nat Commun 23:3706

Kagale S, Nixon J, Khedikar Y, Pasha A, Provart NJ, Clarke WE, Bollina V, Robinson SJ, Coutu C, Hegedus DD, Sharpe AG, Parkin IA (2016) The developmental transcriptome atlas of the biofuel crop Camelina sativa. Plant $\mathbf{J}$ 88:879-854

Kakani R, Fowler J, Haq AU, Murphy EJ, Rosenberger TA, Berhow M, Bailey CA (2012) Camelina meal increases egg n-3 fatty acid content without altering quality or production in laying hens. Lipids 47:519-526

Kahindi RK, Woyengo TA, Thacker PA, Nyachoti CM (2014) Energy and amino acid digestibility of camelina cake fed to finishing pigs. Anim Feed Sci Technol 193:93-101

Karchi H, Shaul O, Galili G (1994) Lysine synthesis and catabolism are coordinately regulated during tobacco seed development. Proc Natl Acad Sci USA 91:2577-2581

Kawakatsu T, Wang S, Wakasa Y, Takaiwa F (2010) Increased lysine content in rice grains by over-accumulation of $\mathrm{BiP}$ in the endosperm. Biosci Biotechnol Biochem 74:2529-2531

Keeler SJ, Maloney CL, Webber PY, Patterson C, Hirata LT, Falco SC, Rice JA (1997) Expression of de novo highlysine alpha-helical coiled-coil proteins may significantly increase the accumulated levels of lysine in mature seeds of transgenic tobacco plants. Plant Mol Biol 34:15-29

Kidd MT, Kerr BJ, Halpin KM, McWard GW, Quarles CL (1998) Lysine levels in starter and grower-finisher diets affect broiler performance and carcass traits. Appl Poult Sci 7:351-358

Kim HJ, Lee JY, Yoon UH, Lim SH, Kim YM (2013) Effects of reduced prolamin on seed storage protein composition and the nutritional quality of rice. Int $\mathrm{J}$ Mol Sci 14:17073-17084

Kohno-Murase J, Murase M, Ichikawa H, Imamura J (1995) Improvement in the quality of seed storage protein by transformation of Brassica napus with an antisense gene for cruciferin. Theor Appl Genet 91:627-631

Kumpaisal R, Hashimoto T, Yamada Y (1987) Purification and characterization of dihydrodipicolinate synthase from wheat suspension cultures. Plant Physiol 85:145-151

Lam HM, Coschigano K, Schultz C, Melo-Oliveira R, Tjagen G, Oliveira I, Ngai N, Hsieh MH, Coruzzi GM (1995) Use of
Arabidopsis mutants and genes to study amide amino acid biosynthesis. Plant Cell 7:887-898

Laskowski RA, Gerick F, Thornton JM (2009) The structural basis of allosteric regulation in proteins. FEBS Lett 583:1692-1698

Lill JR, Ingle ES, Liu PS, Pham V, Sandoval WN (2007) Microwave-assisted proteomics. Mass Spectrom Rev 26:657-671

Liu X, Zhang C, Wang X, Liu Q, Yuan D, Pan G, Sun SS, Tu J (2016) Development of high-lysine rice via endospermspecific expression of a foreign LYSINE RICH PROTEIN gene. BMC Plant Biol 16:147

Long X, Liu Q, Chan M, Wang Q, Sun SS (2013) Metabolic engineering and profiling of rice with increased lysine. Plant Biotechnol J 11:490-501

Lu C, Kang J (2008) Generation of transgenic plants of a potential oilseed crop Camelina sativa by Agrobacteriummediated transformation. Plant Cell Rep 27:273-278

Lyzenga WJ, Harrington M, Bekkaoui D, Wigness M, Hegedus DD, Rozwadowski KL (2019) CRISPR/Cas9 editing of three CRUCIFERIN C homoeologues alters the seed protein profile in Camelina sativa. BMC Plant Biol 19:292

Mertz ET, Bates LS, Nelson OE (1964) Mutant gene that changes protein composition and increases lysine content of maize endosperm. Science 145:279-280

Mitsakos V, Devenish SRA, O'Donnell PA, Gerrard JA, Hutton CA (2011) LC-MS and NMR characterization of the purple chromophore formed in the $o$-aminobenzaldehyde assay of dihydrodipicolinate synthase. Bioorg Med Chem 19:1535-1540

Murashige T, Skoog F (1962) A revised medium for rapid growth and bioassay with tobacco tissue cultures. Physiol Plant 15:473-497

Negrutiu I, Cattoir-Reynearts A, Verbruggen I, Jacobs M (1984) Lysine overproducer mutants with an altered dihydrodipicolinate synthase from protoplast culture of Nicotiana sylvestris (Spegazzini and Comes). Theor Appl Genet 68:11-20

Nielsen HK, Hurrell RF (1985) Tryptophan determination of food proteins by HPLC after alkaline hydrolysis. J Sci Food Agric 36:893-907

Nguyen T, Liu XJ, Derocher J (2014) Floral dip method for transformation of Camelina. United States Patent US $8,779,238 \mathrm{~B} 2$

Pettersen EF, Goddard TD, Huang CC, Couch GS, Greenblatt DM, Meng EC, Ferrin TE (2004) UCSF Chimera-a visualization system for exploratory research and analysis. J Comput Chem 25:1605-1612

Remmert M, Biegert A, Hauser A, Soding J (2012) HHblits: lightning-fast iterative protein sequence searching by HMM-HMM alignment. Nat Methods 9:173-175

Rice EA, Bannon GA, Glenn KC, Jeong SS, Sturman EJ, Rydel TJ (2008) Characterization and crystal structure of lysine insensitive Corynebacterium glutamicum dihydrodipicolinate synthase (cDHDPS) protein. Arch Biochem Biophys 480:111-121

Rozwadowski K, Yang W, Kagale S (2008) Homologous recombination-mediated cloning and manipulation of genomic DNA regions using Gateway and recombineering systems. BMC Biotechnol 8:88 
Schmidt D, Gaziola SA, Boaretto LF, Azevedo RA (2016) Proteomic analysis of mature barley grains from C-hordein antisense lines. Phytochemistry 125:14-26

Shaul O, Galili G (1993) Concerted regulation of lysine and threonine synthesis in tobacco plants expressing bacterial feedback-insensitive aspartate kinase and dihydrodipicolinate synthase. Plant Mol Biol 23:759-768

Shaver JM, Bittel DC, Sellner JM, Frisch DA, Somers DA, Gengenbach BG (1996) Single-amino acid substitutions eliminate lysine inhibition of maize dihydrodipicolinate synthase. Proc Natl Acad Sci USA 93:1962-1966

Silk GW, Matthews BF, Somers DA, Gengenbach BG (1994) Cloning and expression of the soybean DapA gene encoding dihydrodipicolinate synthase. Plant Mol Biol 26:989-993

Silk GW, Matthews BF (1997) Soybean DapA mutations encoding lysine-insensitive dihydrodipicolinate synthase. Plant Mol Biol 33:931-933

Sjödahl S, Gustavsson HO, Rödin J, Lenman M, Höglund AS, Rask L (1993) Cruciferin gene families are expressed coordinately but with tissue-specific differences during Brassica napus seed development. Plant Mol Biol 23:1165-1176

Skovpen YV, Palmer DR (2013) Dihydrodipicolinate synthase from Campylobacter jejuni: kinetic mechanism of cooperative allosteric inhibition and inhibitor-induced substrate cooperativity. Biochemistry 52:5454-5462

Troeng S (1955) Oil determination of oilseed. Gravimetric routine method. J Am Oil Chem Soc 32:124-126

Tuan YH, Philips RD (1997) Optimized determination of cystine/cysteine and acid-stable amino acids from a single hydrolysate of casein- and sorghum-based diet and digesta samples. J Agric Food Chem 45:3535-3540

Vauterin M, Frankard V, Jacobs M (2000) Functional rescue of a bacterial dapA auxotroph with a plant cDNA library selects for mutant clones encoding a feedback-insensitive dihydrodipicolinate synthase. Plant J 21:239-248

Vollmann J, Eynck C (2015) Camelina as a sustainable oilseed crop: contributions of plant breeding and genetic engineering. Biotechnol J 10:525-535

Wallsgrove RM, Mazelis M (1980) The enzymology of lysine biosynthesis in higher plants: Complete localization of the regulatory enzyme dihydrodipicolinate synthase in the chloroplasts of spinach leaves. FEBS Lett 116:189-192

Wang J, Chen L, Liu QQ, Sun SSM, Sokolov V, Wang YP (2011) Transformation of LRP gene into Brassica napus mediated by Agrobacterium tumefaciens to enhance lysine content in seeds. Genetika 47:1616-1621

Wang W, Xu M, Wang G, Galili G (2018) New insights into the metabolism of aspartate-family amino acids in plant seeds. Plant Reprod 31:203-211

Wilson AC, Halver JE (1986) Protein and amino acid requirements of fishes. Annu Rev Nutr 6:225-244

Wong HW, Liu Q, Sun SS (2015) Biofortification of rice with lysine using endogenous histones. Plant Mol Biol 87:235-248

Wu K, Hu M, Martin T, Wang C, Li XQ, Tian L, Brown D, Miki B (2003) The cryptic enhancer elements of the $t C U P$ promoter. Plant Mol Biol 51:351-362

Yu J, Peng P, Zhang X, Zhao Q, Zhu D, Sun X, Liu J, Ao G (2005) Seed-specific expression of the lysine-rich protein gene sb401 significantly increases both lysine and total protein content in maize seeds. Food Nutr Bull 26:427-431

Yugari Y, Gilvarg C (1965) The condensation step in diaminopimelate synthesis. J Biol Chem 240:4710-4716

Zhang Y, Schernthaner J, Labbé N, Hefford MA, Zhao J, Simmonds DH (2014) Improved protein quality in transgenic soybean expressing a de novo synthetic protein, MB-16. Transgenic Res 23:455-467

Zhu X, Galili G (2003) Increased lysine synthesis coupled with a knockout of its catabolism synergistically boosts lysine content and also trans regulates the metabolism of other amino acids in Arabidopsis seeds. Plant Cell 15:845-853

Zhu X, Galili G (2004) Lysine metabolism is concurrently regulated by synthesis and catabolism in both reproductive and vegetative tissues. Plant Physiol 135:129-136

Zubr J (2003) Dietary fatty acids and amino acids of Camelina sativa seed. J Food Qual 26:451-462

Publisher's Note Springer Nature remains neutral with regard to jurisdictional claims in published maps and institutional affiliations. 